\title{
Influência de tensões compressivas na pressão de precompactação e no índice de compressão do solo
}

\author{
Vera R. M. Macedo ${ }^{1}$, Apolino J. N. da Silva ${ }^{2} \&$ Mário S. V. Cabeda ${ }^{3}$
}

\begin{abstract}
RESU MO
Este trabal ho objetivou determinar os parâmetros de compressibilidade de um Argissolo Vermelho através de ensaios de compressão uniaxial, com três tempos de aplicação de pressão compressiva (7,5 s, 1 e $2 \mathrm{~min}$ ) em duas umidades do solo $(0,113$ e 0,164 kg kg-1) e verificar o comportamento mecânico do solo após o alívio das cargas. 0 Argissolo Vermelho foi coletado em experimento conduzido em parcelas fisicamente degradadas e recuperadas na Estação Experimental Agronômica da UFRGS. A condição de degradação apresentou os maiores valores de pressão de precompactação em relação à condição fisicamente recuperada, nas duas umidades estudadas. Não houve diferença significativa entre os valores das pressões de precompactação do solo determinados com as curvas de compressão nos tempos de aplicação da pressão compressiva de 7,5 s, 1 e 2 min, nas duas umidades e nas duas condições físicas do solo. A condição fisicamente recuperada apresentou maior índice de compressão em relação à condição degradada em ambas as umidades. 0 alívio promovido pela remoção das pressões compressivas impostas ao solo promoveu um pequeno incremento na porosidade total do solo e decréscimo na sua densidade.
\end{abstract}

Palavras-chave: parâmetros de compressibilidade, porosidade total, densidade do solo

\section{Influence of compressive tensions on the precompaction pressure and on the compression index of the soil}

\begin{abstract}
The objectives of this study were to determine the compressibility parameters of an Acrisol through uniaxial compression tests, with three application times of compressive pressure $(7.5 \mathrm{~s}, 1$ and $2 \mathrm{~min})$ and in two moisture contents $(0.113$ and $\left.0.164 \mathrm{~kg} \mathrm{~kg}^{-1}\right)$, and to verify the mechanical soil behavior after the removal of the loads. The Acrisol was collected in an experiment conducted in areas physically degraded and upgraded, in the Agricultural Experimental Station of the UFRGS. The physically degraded condition presented the highest values of precompaction pressure in relation to the upgraded condition, for both moisture contents. There was no significant difference among the values of precompaction pressure determined with the soil compression curve for the times of $7.5 \mathrm{~s}, 1$ and 2 min compressive pressure application in both moisture contents as well in both physical conditions of the soil. The physically upgraded condition presented higher compression index compared to the degraded condition in both moisture contents. The relief promoted by the removal of the compressive pressures imposed on the soil promoted a small increment in the total porosity and reduction in the bulk density.
\end{abstract}

Key words: compressibility parameters, total porosity, bulk density

\footnotetext{
${ }^{1}$ Engenheira Agrônoma, M. Sc. em Ciências do Solo. Instituto Rio-Grandense do Arroz/IRGA. CP 29, CEP 94930-030, Cachoeirinha, RS. Fone: (51) $3470-0600$. E-mail: vera-macedo@irga.rs.gov.br

2 Unidade Acadêmica Especializada em Ciências Agrárias Escola Agrícola de Jundiaí/U FRN . CP 07, CEP 59280-000, Macaíba, RN. Fone: (84) $3643-2235$. E-mail: ajndas@ufrnet.br

3 Departamento de Solos/UFRGS. CP 776, CEP 90001-970, Porto Alegre, RS. Fone: (051) 3316-6851. E-mail: mscabeda@uol.com.br
} 


\section{INTRODUÇÃO}

O processo de degradação física de solos intensamente preparados no sul do Brasil se manifesta pela perda da qualidade da estrutura, com o aparecimento de finas crostas superficiais e camadas compactadas situadas entre 10 e $30 \mathrm{~cm}$ de profundidade (Cabeda, 1984). Esta condição de degradação do espaço estrutural do solo reduz a taxa de infiltração de água e aumenta a taxa de escoamento superficial, refletindo-se em maiores taxas de erosão, de poluição ambiental e na redução da produtividade agrícola.

Normalmente, um solo fisicamente recuperado apresenta um bom volume de macroporos devido à ação de raízes, macro e micro-organismos presentes (Medeiros, 1985). Este solo tende a manter-se mais úmido por efeito da cobertura de resíduos culturais deixados sobre a sua superfície em sistemas conservacionistas de manejo (Silva, 1986; Lima et al., 2006). Quando uma pressão compressiva é aplicada sobre o solo, os principais efeitos se manifestam pela redução do espaço poroso, especialmente de macroporos (Dexter et al., 2007). Um solo com elevada macroporosidade é mais facilmente comprimido pelo tráfego que um solo com microporosidade visto que, no primeiro há menos pontos de contato partícula-partícula para conferir mais resistência mecânica à pressão compressiva imposta (Keller \& Arvidsson, 2007; Krummelbein et al., 2008). Sob determinada pressão os microporos podem estar cheios de água e, em virtude de sua baixa condutividade hidráulica e incompressibilidade da água, são capazes de resistir mais a tensões em curtos intervalos de tempo que macroporos cheios de ar (Kutýleka et al., 2006; Silva et al., 2009).

A redução da porosidade do solo decorrente de pressões externas exercidas sobre ele por máquinas agrícolas tem sido simulada através do teste de compressão uniaxial, obtendose a curva de compressão do solo, a qual representa graficamente a relação entre algum parâmetro relacionado com a estrutura do solo, como índice de vazios, porosidade ou densidade do solo em função da pressão vertical aplicada (Cavalieri et al., 2008; Krummelbein et al., 2008). Através da curva de compressão se determina a pressão de precompactação do solo, que indica a capacidade de suporte de carga do solo, correspondendo à pressão máxima que o solo pode suportar sem sofrer compactação (Stone \& Larson, 1980).

A curva de compressão do solo tem sido determinada, no entanto, com diferentes tempos de aplicação da pressão vertical compressiva, com carregamentos que duram 5 min (Silva et al., 2000, Lima et al., 2004; Braida et al., 2008), 7 min (Silva \& Cabeda, 2006), 30 min (Arvidsson, 1998; Veiga et al., 2007) e $2 \mathrm{~h}$ (Canarachea et al., 2000). A maioria desses autores argumenta que referidos tempos de aplicação de cada pressão vertical nas amostras foram necessários para o solo atingir cerca de $98 \%$ da deformação máxima.

$\mathrm{O}$ intervalo de tempo correspondente à passagem das máquinas agrícolas exercendo pressões em uma área sobre a superfície do solo nas atividades de cultivo, é muito curto, mesmo se se considerar o somatório dos tempos de várias passadas do trator, na mesma área. Os solos agrícolas bem manejados são suficientemente porosos, com o espaço estrutural contendo macroporos não são saturados e com distri- buição heterogênea de diâmetro nominal de partículas. Tais condições favorecem compactações quase que instantâneas, devido às pressões exercidas pelas máquinas agrícolas nas atividades de cultivo e colheita das culturas (Macedo, 1993; Koch et al., 2008).

Poucos trabalhos têm determinado a curva de compressão do solo aplicando tempos curtos (0,5 a 1,0 min) de carregamentos no teste de compressão uniaxial, simulando o tempo de compressão do solo imposta por máquinas agrícolas nas atividades de cultivo (Etana et al., 1997; Kutýleka et al., 2006). Para que o teste de compressão uniaxial simule com maior fidelidade a compressão do solo exercida pelas máquinas agrícolas, são necessários estudos no sentido de se determinar os parâmetros de compressibilidade através de curvas de compressão do solo obtidas com a aplicação de pressões compressivas em tempos mais curtos.

A degradação física do solo pela compressão depende também da intensidade do tráfego, em que muitas passagens das máquinas agrícolas sobre a mesma área de solo reduzem a porosidade e o diâmetro nominal dos poros, porém com menor decréscimo a cada passagem, ou seja, a cada aplicação de tensão compressiva (Zhang et al., 2005), embora essas relações sejam altamente dependentes das condições do solo, especialmente da umidade, da consistência, porosidade e macroporosidade iniciais (Imhoff et al., 2004; Figueiredo et al., 2009). Em solos inicialmente soltos e com umidade próxima à ótima para a compactação (umidade que confere plasticidade ao solo), o incremento da densidade durante a primeira passagem é maior que nas subseqüentes, ao passo que em solos com resistência inicial maior, a compactação causada pela primeira passagem do veículo difere pouco das passagens posteriores (Trautner \& Arvidsson, 2003). Este comportamento mecânico pode ser estudado no ensaio de compressão uniaxial, após a retirada das pressões verticais aplicadas no teste, simulando a passagem das máquinas nos solos utilizados na agricultura (Silva et al., 2002).

Com tal entendimento, objetivou-se avaliar o tempo de aplicação da pressão compressiva nos parâmetros de compressibilidade de um solo Argissolo Vermelho fisicamente recuperado e degradado, em dois teores de umidade, e estudar o comportamento mecânico do solo após o alívio das pressões compressivas.

\section{MATERIAL E MÉTODOS}

O trabalho foi desenvolvido na Estação Experimental Agronômica da Universidade Federal do Rio Grande do Sul UFRGS, no município de Eldorado do Sul, RS, em experimento instalado e manejado desde 1983 (Medeiros, 1985), em um Argissolo Vermelho Distrófico típico (EMBRAPA, 2006), cujo perfil, em condições naturais, apresenta no horizonte A: $470 \mathrm{~g} \mathrm{~kg}^{-1}$ de areia, $220 \mathrm{~g} \mathrm{~kg}^{-1}$ de silte, $310 \mathrm{~g} \mathrm{~kg}^{-1}$ de argila, 1,6 $\mathrm{cmol}_{\mathrm{c}} \mathrm{kg}^{-1} \mathrm{de} \mathrm{Ca}^{2+}, 1,3 \mathrm{cmol}_{\mathrm{c}} \mathrm{kg}^{-1} \mathrm{de} \mathrm{Mg}^{2+}, 0,41 \mathrm{cmol}_{\mathrm{c}} \mathrm{kg}^{-1}$ de $\mathrm{K}^{+}, 0,15 \mathrm{cmol}_{\mathrm{c}} \mathrm{kg}^{-1}$ de $\mathrm{Na}^{+}$e valor T igual a $8,5 \mathrm{cmol}_{\mathrm{c}} \mathrm{kg}^{-1}$ (Carpenedo, 1994). O clima da área estudada, segundo classificação de Koeppen, é do tipo Cfa, clima subtropical com verão quente, com temperatura media anual variando de 18 a 
$20{ }^{\circ} \mathrm{C}$ e precipitação média anual variando de 1600 a $1700 \mathrm{~mm}$ (SEPLAG, 2010).

A área em que foi instalado o experimento vinha sofrendo um preparo intensivo e inadequado por dez anos consecutivos e o solo apresentava importante degradação física, descrita por Medeiros (1985). Para atender aos objetivos do trabalho, utilizaram- -se as áreas de um experimento em blocos casualizados, com três repetições. Cada bloco se constitui de duas parcelas principais, com dois níveis de compactação, sendo o solo considerado descompactado (fisicamente recuperado) aquele em que a camada compactada subsuperficial foi rompida através de aração até a profundidade de $25 \pm 5 \mathrm{~cm}$, seguida de quatro gradagens cruzadas, e o solo considerado compactado (fisicamente degradado) aquele em que foram efetuadas quatro gradagens, sem romper a camada compactada subsuperficial.

As amostras de solo na condição fisicamente degradada foram coletadas em três parcelas compactadas, de $5 \times 4 \mathrm{~m}$ cada uma, utilizadas com o sistema pousio-milho, sem aplicação de nitrogênio. As amostras de solo na condição fisicamente recuperada foram coletadas em três parcelas de solo descompactado, também de 5 x 4 m cada uma, e ocupadas ininterruptamente durante 9 anos, por siratro (Macroptilium atropurpureum), também sem aplicação de nitrogênio.

As amostras indeformadas de solo foram coletadas entre 10 e $12 \mathrm{~cm}$ de profundidade com anéis metálicos rígidos de $5 \mathrm{~cm}$ de diâmetro e $2 \mathrm{~cm}$ de altura, com auxílio de um amostrador e acondicionadas em sacos plásticos sobre serragem, evitando-se perturbações durante o transporte para o laboratório. As quatro amostras em cada sítio de amostragem foram coletadas reservando-se duas amostras para cada teor de umidade adotado. Cada amostra foi saturada por ascensão capilar de água durante 24 h e colocada em câmara de pressão até equilíbrio em valores equivalentes a -700 e $-20 \mathrm{kPa}$ de potencial matricial, atingindo umidades gravimétricas médias de 0,113 e $0,164 \mathrm{~kg} \mathrm{~kg}^{-1}$, conforme metodologia descrita por Richards (1965). A umidade gravimétrica de $0,11 \mathrm{~kg} \mathrm{~kg}^{-1}$ correspondente ao limite inferior de plasticidade desse solo, foi determinado pelo método descrito por EMBRAPA (1997). Atingidos tais valores de umidade, as amostras foram imediatamente submetidas ao ensaio de compressão confinada, utilizando-se a prensa de compressão uniaxial, conforme metodologia descrita em Brasil (1971). A sequência de cargas aplicadas foi de 25, 50, 100, 200, 400 e $500 \mathrm{kPa}$, com leituras realizadas aos 7,5 s, 1 e 2 min. A cada dois minutos a amostra recebeu um incremento de carga até atingir $500 \mathrm{kPa}$. O índice de vazios (e) foi calculado pela expressão 1, conforme Brasil (1971):

$$
\mathrm{e}=\frac{\mathrm{h}}{\mathrm{h}_{\mathrm{s}}}-1
$$

em que h é a altura da amostra e $\mathrm{h}_{\mathrm{s}}$ é a altura reduzida da amostra após a compressão, ambas expressas em $\mathrm{cm}$.

A curva de compressão do solo foi constituída com os valores de índices de vazios (e) localizados no eixo das ordenadas e com os valores das pressões aplicadas $(\sigma)$ no eixo das abcissas, esses em escala logarítmica.
A densidade de partículas do solo (Dp) foi determinada pelo método do balão volumétrico e a densidade do solo (Ds) obtida pela relação entre a massa do solo secado em estufa e o volume do anel usado na coleta (EMBRAPA, 1997). A densidade do solo após a compressão uniaxial foi determinada pela expressão 2, conforme Brasil (1971):

$$
\text { Ds }=\frac{\text { Dp }}{(1+e)}
$$

A porosidade do solo $(\mathrm{P})$, inicial e após a compressão, foi obtida pela expressão 3, indicada por EMBRAPA (1997):

$$
\mathrm{P}=\left(1-\frac{\mathrm{Ds}}{\mathrm{Dp}}\right)
$$

Com base nos resultados, as curvas de compressibilidade do solo foram traçadas e determinada a pressão de precompactação pelo método Pacheco Silva (ABNT, 1990). Obteve-se o índice de compressão (Cc) conforme Brasil (1971), pela expressão 4:

$$
\mathrm{Cc}=\frac{-\Delta \mathrm{e}}{\Delta \log \mathrm{P}}
$$

em que:

$\Delta \mathrm{e}$ - variação do índice de vazios na reta virgem

$\Delta \log \mathrm{P}$ - variação do logaritmo da pressão aplicada no intervalo correspondente

A análise estatística seguiu o modelo de um delineamento de blocos casualizados, sendo a comparação entre as médias de tratamentos feita pelo teste de Tukey, a nível de 5\% de probabilidade, usando-se o software Assistat (Silva, 1996).

\section{RESULTADOS E DISCUSSÃO}

\section{Parâmetros de compressibilidade do solo}

A Tabela 1 mostra os valores de pressão de precompactação em ambas as condições físicas do solo, determinados com as curvas de compressão no tempo de 2 min de aplicação da pressão compressiva no teste de compressão uniaxial. Houve efeito significativo da condição física do solo, degradado e recuperado, e do teor de umidade sobre a pressão de precompactação das amostras no citado tempo. A influência da umidade foi significativa nas duas condições físicas do solo (degradado e recuperado), com maiores valores de pressão de precompactação nos menores teores de umidade verificando-se, desta forma, a maior resistência do solo às pressões externas, na medida em que diminui a umidade do solo. Resultados semelhantes foram encontrados por Severiano et al. (2010), que observaram valores mais elevados de pressão de precompactação nos menores teores de umidade de um Argissolo Vermelho Amarelo cultivado com capim-tifton.

O solo fisicamente degradado apresentou os maiores valores de pressão de precompactação (170,0 e 139,0 kPa para os teores de umidade de 0,113 e $0,164 \mathrm{~kg} \mathrm{~kg}^{-1}$ respectivamente), em relação ao solo recuperado (Tabela 1); isto reflete a 
história de pressões sofridas pelo solo degradado, que apresenta um grau maior de compactação devido às pressões aplicadas pelas máquinas agrícolas nas operações do preparo (Macedo, 1993), conferindo-lhe maior capacidade de suporte de cargas.

Tabela 1. Pressões de precompactação $(\mathrm{kPa})$ em Argissolo Vermelho fisicamente degradado e recuperado, obtidas com tempo de 2,0 min de aplicação de pressão compressiva, em duas umidades

\begin{tabular}{ccc}
\hline \multirow{2}{*}{ Condição física do solo } & \multicolumn{2}{c}{ Umidade Gravimétrica* - $\mathbf{~ k g ~ k g - 1 ~}^{-\mathbf{0}}$} \\
\cline { 2 - 3 } Degradado & $\mathbf{0 , 1 1 3}$ & $\mathbf{0 , 1 6 4}$ \\
Recuperado & $170,0 \mathrm{Aa}$ & $139,0 \mathrm{Ba}$ \\
& $109,0 \mathrm{Ab}$ & $79,0 \mathrm{Bb}$ \\
\hline
\end{tabular}

* Valores médios de umidade de seis repetições. Médias seguidas de letras maiúsculas na mesma linha e de letras minúsculas na mesma coluna não diferem entre si, a nível de $5 \%$ de significância, pelo teste de Tukey

A Tabela 2 mostra que não houve diferença significativa entre os valores das pressões de precompactação, determinados com as curvas de compressão nos tempos de aplicação da pressão compressiva de 7,5 s, 1 e 2 min, nas duas condições físicas do solo (degradado e recuperado) e nos dois teores de umidade. Este resultado indica que a pressão de precompactação determinada com o ensaio de compressão uniaxial no Argissolo Vermelho estudado, pode ser determinada em tempos mais curtos de aplicação das tensões compressivas, podendo-se realizar um número maior de ensaios em menor período de tempo, possibilitando o uso de maior número de repetições em estudos futuros; outra implicação deste resultado é que o ensaio realizado em curto período de tempo de aplicação das pressões compressivas está mais em acordo com a realidade que ocorre em campo, no qual a passagem das máquinas agrícolas, aplicando-se pressão externa em determinada área do solo, corresponde a frações de segundos.

Tabela 2. Pressões de precompactação (kPa) em Argissolo Vermelho fisicamente degradado e recuperado em função do tempo de aplicação da pressão compressiva, nas umidades médias de 0,113 e 0,164 kg kg-1

\begin{tabular}{cccc}
\hline $\begin{array}{c}\text { Condição física } \\
\text { do solo }\end{array}$ & \multicolumn{3}{c}{ Tempo de aplicação da pressão compressiva } \\
\cline { 2 - 4 } & $\mathbf{7 , 5} \mathbf{~ s}$ & $\mathbf{1} \mathbf{~ m i n}$ & $\mathbf{2} \mathbf{~ m i n}$ \\
& \multicolumn{3}{c}{$\mathrm{Ug}=0,113 \mathrm{~kg} \mathrm{~kg}^{-1}$} \\
Degradado & $153,3 \mathrm{Aa}$ & $163,7 \mathrm{Aa}$ & $170,0 \mathrm{Aa}$ \\
Recuperado & $118,7 \mathrm{Ab}$ & $135,3 \mathrm{Ab}$ & $139,0 \mathrm{Ab}$ \\
\hline & & $\mathrm{Ug}=0,164 \mathrm{~kg} \mathrm{~kg}^{-1}$ \\
Degradado & $113,7 \mathrm{Aa}$ & $107,0 \mathrm{Aa}$ & $109,0 \mathrm{Aa}$ \\
Recuperado & $88,3 \mathrm{Ab}$ & $77,0 \mathrm{Ab}$ & $79,0 \mathrm{Ab}$ \\
\hline
\end{tabular}

* Valores médios de umidade de seis repetições. Médias seguidas de letras maiúsculas na mesma linha e de letras minúsculas na mesma coluna não diferem entre si, a nível de $5 \%$ de significância, pelo teste de Tukey

Na Tabela 3 se encontram os valores dos índices de compressão do solo determinados com a curva de compressão no tempo de 2 min de aplicação da pressão compressiva. O índice de compressão do solo, que corresponde à inclinação da reta de compressão virgem, é usado como indicador da compressibilidade do solo, sendo um solo tanto mais compressível quanto maior o seu índice de compressão.
Houve efeito significativo do teor de umidade do solo sobre o índice de compressão na condição fisicamente recuperada, com o maior valor do índice de compressão do solo $(0,310)$ ocorrendo no teor de umidade mais elevada $\left(0,164 \mathrm{~kg} \mathrm{~kg}^{-1}\right)$, o que demonstra a menor resistência do solo à compressão à medida em que aumenta a umidade no solo (Tabela 3). Braida et al. (2010) também verificaram aumento no índice de compressão do solo com o acréscimo do teor de umidade até $0,160 \mathrm{~kg} \mathrm{~kg}^{-1}$, em um Argissolo Vermelho Amarelo. Este fenômeno ocorre pelo fato da água agir como agente lubrificante, favorecendo o deslocamento, o rearranjo orientado e a união das partículas, resultando em uma compressibilidade maior do solo (Al-Shayea, 2001; Mooney \& Nipattasuk, 2003).

A condição de solo degradado apresentou menores valores de índice de compressão (0,077 e 0,110 para os teores de umidade de 0,113 e $0,164 \mathrm{~kg} \mathrm{~kg}^{-1}$ respectivamente) em relação à condição fisicamente recuperada, ou seja, menor compressibilidade da condição degradada (Tabela 3), como consequência, possivelmente, da maior densidade inicial em condições de degradação do solo (Macedo, 1993), que proporciona um número maior de pontos de contato entre as partículas e maior resistência à compressão. Silva et al. (2002) estudando o efeito da densidade inicial na compressibilidade de um Argissolo Vermelho Amarelo, também constataram menores valores de índice de compressão quando o solo apresentava maior estado inicial de compactação, fato indicado pelos maiores valores de densidade inicial.

Tabela 3. Índices de compressão em Argissolo Vermelho fisicamente degradado e recuperado, obtidos com tempo de 2,0 min de aplicação de pressão compressiva, em duas umidades

\begin{tabular}{ccc}
\hline \multirow{2}{*}{ Condição física do solo } & \multicolumn{2}{c}{ Umidade Gravimétrica* - $\mathbf{~ k g ~ l g}^{-\mathbf{1}}$} \\
\cline { 2 - 3 } & $\mathbf{0 , 1 1 3}$ & $\mathbf{0 , 1 6 4}$ \\
Degradado & $0,077 \mathrm{Ab}$ & $0,110 \mathrm{Ab}$ \\
Recuperado & $0,124 \mathrm{Ba}$ & $0,310 \mathrm{Aa}$ \\
\hline
\end{tabular}

* Valores médios de umidade de seis repetições. Médias seguidas de letras maiúsculas na mesma linha e de letras minúsculas na mesma coluna não diferem entre si, a nível de $5 \%$ de significância, pelo teste de Tukey

Não houve diferença significativa entre os valores dos índices de compressão do solo determinados com as curvas de compressão nos tempos de aplicação da pressão compressiva de 7,5 s, 1 min e 2 min, em ambos os teores de umidade (Tabela 4). Semelhante aos dados de pressão de precompactação (Tabela 2), os resultados dos índices de compressão do solo mostram que o ensaio de compressão uniaxial no Argissolo Vermelho estudado pode ser determinado em tempos mais curtos de aplicação das tensões compressivas, podendo-se realizar um número maior de ensaios em menor período de tempo, ou possibilitando o uso de maior número de repetições em um mesmo período de tempo em estudos futuros.

\section{Variação da porosidade e densidade do solo após a retirada das pressões compressivas}

O alívio promovido pela remoção das cargas aplicadas ao solo no teste de compressão uniaxial, promoveu um pequeno incremento na porosidade total do solo (Tabela 5) e de- 
Tabela 4. Índices de compressão em Argissolo Vermelho fisicamente degradado e recuperado em função do tempo de aplicação da pressão compressiva nos teores médios de umidade de 0,113 e 0,164 kg kg-1

\begin{tabular}{|c|c|c|c|}
\hline \multirow{2}{*}{$\begin{array}{l}\text { Condição física } \\
\text { do solo }\end{array}$} & \multicolumn{3}{|c|}{ Tempo de aplicação da pressão compressiva } \\
\hline & $7,5 \mathrm{~s}$ & $1 \mathrm{~min}$ & $2 \mathrm{~min}$ \\
\hline & \multicolumn{3}{|c|}{$\mathrm{Ug}=0,113 \mathrm{~kg} \mathrm{~kg}^{-1}$} \\
\hline Degradado & $0,067 \mathrm{Ab}$ & $0,067 \mathrm{Ab}$ & $0,077 \mathrm{Ab}$ \\
\hline \multirow[t]{2}{*}{ Recuperado } & $0,119 \mathrm{Aa}$ & $0,129 \mathrm{Aa}$ & $0,124 \mathrm{Aa}$ \\
\hline & \multicolumn{3}{|c|}{$\mathrm{Ug}=0,164 \mathrm{~kg} \mathrm{~kg}^{-1}$} \\
\hline Degradado & $0,110 \mathrm{Ab}$ & $0,110 \mathrm{Ab}$ & $0,110 \mathrm{Ab}$ \\
\hline Recuperado & $0,305 \mathrm{Aa}$ & $0,305 \mathrm{Aa}$ & $0,305 \mathrm{Aa}$ \\
\hline
\end{tabular}

* Valores médios de umidade de seis repetições. Médias seguidas de letras maiúsculas na mesma linha e de letras minúsculas na mesma coluna não diferem entre si, a nível de $5 \%$ de significância, pelo teste de Tukey

créscimo na sua densidade (Figura 1).

$\mathrm{O}$ acréscimo médio na porosidade total das amostras de solo antes recuperado, foi de 1,0 e $0,5 \%$, quando a compressão havia ocorrido em umidade de 0,165 e $0,109 \mathrm{~kg} \mathrm{~kg}^{-1}$, respectivamente. No solo fisicamente degradado a recuperação média na porosidade total foi de $1,1 \mathrm{e} 0,8 \%$, respectivamente às umidades de 0,163 e $0,117 \mathrm{~kg} \mathrm{~kg}^{-1}$ (Tabela 5).

Tabela 5. Porosidade total do solo após a retirada das pressões compressivas evariação percentual da porosidade em Argissolo Vermelho fisicamente degradado e recuperado, em umidades gravimétricas equivalentes a - 700 e -20 $\mathrm{kPa}$ de potencial matricial

\begin{tabular}{|c|c|c|c|c|c|}
\hline \multirow{2}{*}{$\begin{array}{l}\text { Condiç̧ão } \\
\text { física do solo }\end{array}$} & \multirow{2}{*}{$\begin{array}{c}\text { Porosidade } \\
\text { total após } \\
\text { compressão } \\
\left(\mathrm{m}^{3} \mathrm{~m}^{-3}\right)^{*}\end{array}$} & \multirow{2}{*}{$\begin{array}{c}\text { Porosidade } \\
\text { total após } \\
\text { retirada das } \\
\text { pressões } \\
\text { compressivas } \\
\left(\mathrm{m}^{3} \mathrm{~m}^{-3}\right)\end{array}$} & \multirow{2}{*}{$\begin{array}{c}\text { Variação } \\
(\%)\end{array}$} & \multicolumn{2}{|c|}{$\begin{array}{c}\mathrm{Ug} \\
\left(\mathrm{kg} \mathrm{kg}^{-1}\right)\end{array}$} \\
\hline & & & & $-700 \mathrm{kPa}$ & $-20 \mathrm{kPa}$ \\
\hline Degradado & 0,346 & 0,354 & 0,8 & 0,117 & \\
\hline Recuperado & 0,366 & 0,371 & 0,5 & 0,109 & \\
\hline Degradado & 0,292 & 0,303 & 1,1 & & 0,163 \\
\hline Recuperado & 0,278 & 0,288 & 1,0 & & 0,165 \\
\hline
\end{tabular}

* Médias de três repetições

A densidade do solo apresentou redução média de $0,02 \mathrm{~kg} \mathrm{dm}^{-3}$ na condição de solo recuperado e de $0,03 \mathrm{~kg} \mathrm{dm}^{-3}$ no solo em condição degradada (Figura 1). Stone \& Larson (1980) encontraram valores de decréscimo de densidade do solo inferiores a $0,05 \mathrm{~kg} \mathrm{dm}^{-3}$, que consideraram negligíveis. Esses autores enfatizam que, como os solos usados para a agricultura sofrem processos sucessivos de recompressão pela mecanização agrícola, a tendência é que a recuperação nos valores da porosidade total ou o decréscimo na densidade do solo seja menor a cada ciclo compressão-descarregamento, devido ao maior rearranjo das partículas do solo e ao aumento das forças de atrito interpartículas, que resistem ao alívio da tensão compressiva. Um rearranjo adicional das partículas ocorre a cada recarregamento e os valores de densidade do solo tendem a estabilizar.

Diante disso, fica evidente que, pela remoção da pressão aplicada, o solo não retorna às condições de porosidade e densidade anteriores à compressão. Neste trabalho é preciso considerar que a condição de solo fisicamente recuperado, que apresente porosidade total elevada e constituída por

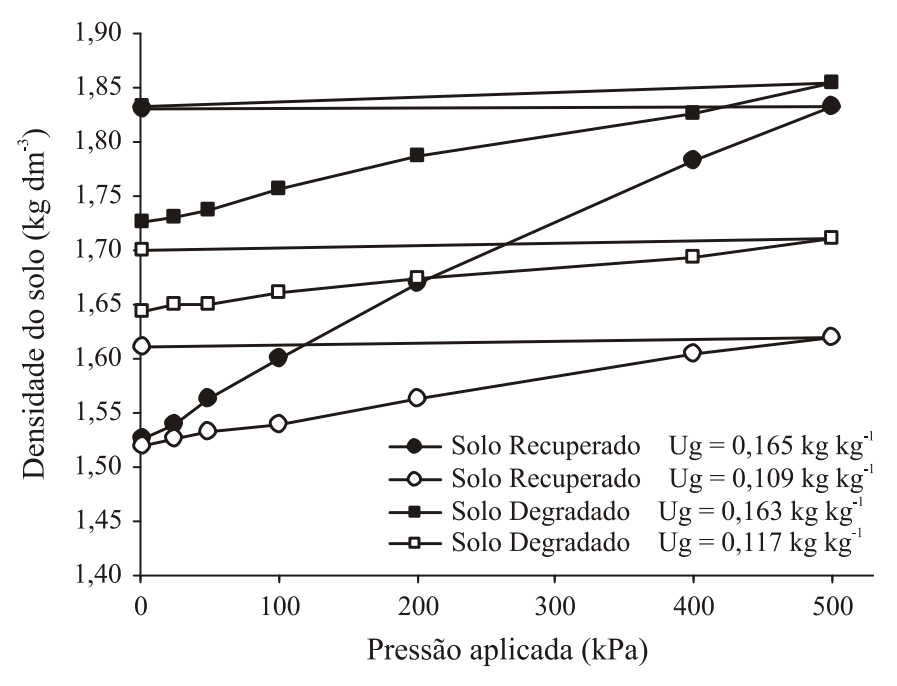

Figura 1. Variação da densidade do solo após dois minutos da retirada das pressões compressivas em Argissolo Vermelho fisicamente degradado e recuperado, em dois teores de umidade

macroporos em valores significativos, terá a sua porosidade rapidamente diminuída na compressão, razão por que é necessário compreender o comportamento mecânico do solo para se buscar maneiras de compatibilizar as vantagens do uso racional das máquinas agrícolas com seus efeitos compressivos no solo. É oportuno, também, o investimento na recuperação de solos fisicamente degradados, aliado a pesquisas cujos resultados possam conferir, ao solo, de maneira concomitante, uma porosidade e uma distribuição de diâmetro nominal de poros adequada, bem como maior resistência à compressão pelas máquinas e a consequente compactação.

\section{CONCLUSÕES}

1. A umidade influenciou de forma significativa as condições físicas do solo degradado e recuperado, com maiores valores de pressão de precompactação nos menores teores de umidade. A condição fisicamente degradada apresentou os maiores valores de pressão de precompactação em relação à condição recuperada, nos dois teores de umidade.

2. Os tempos de aplicação da pressão compressiva não influenciaram os valores da pressão de precompactação do solo nos dois teores de umidade nem nas duas condições físicas do solo.

3. O solo fisicamente recuperado mostrou-se mais compressível, apresentando maior índice de compressão em relação ao solo fisicamente degradado.

4. O alívio promovido pela remoção das tensões compressivas impostas ao solo promoveu um pequeno incremento na porosidade total do solo e decréscimo na sua densidade do solo.

\section{AGRADECIMENTOS}

Ao professor Luiz Renato D'Agostini, da UFSC, pelas sugestões, e ao professor João Mielniczuk, da UFRGS, pela cessão da área experimental. 


\section{LITERATURA CITADA}

Al-Shayea, N. A. The combined effect of clay and moisture content on the behavior of remolded unsaturated soils. Engineering Geology, v.62, p.319-342, 2001.

Arvidsson, J. Influence of soil texture and organic matter content on bulk density, air content, compression index and crop yield in field and laboratory compression experiments. Soil \& Tillage Research, v.49, p.159-170, 1998.

ABNT - Associação Brasileira de Normas Técnicas. Ensaio de adensamento unidimensional. NER-12007. Rio de Janeiro: ABNT, 1990. 13p.

Braida, J. A.; Reichert, J. M.; Dalvan J. Reinert, D. J.; Veiga, M. Teor de carbono orgânico e a susceptibilidade à compactação de um Nitossolo e um Argissolo. Revista Brasileira de Engenharia Agrícola e Ambiental, v.14, n.2, p.131-139, 2010.

Braida, J. A.; Reichert, J. M.; Reinert, D. J.; Sequinatto, L. Elasticidade do solo em função da umidade e do teor de carbono orgânico. Revista Brasileira de Ciência do Solo, v. 32, p.477-485, 2008.

Brasil. Ministério dos Transportes. Departamento Nacional de Estradas de Rodagem. Adensamento de solos: instruções de ensaio. DNER-IE 05.71. Brasília: DNER, 1971. 16p.

Cabeda, M. S. V. Degradação física e erosão do solo. In: Simpósio de Manejo do Solo e Plantio Direto no Sul do Brasil, 3, 1984, Passo Fundo. Anais... Passo Fundo: Univerdidade de Passo Fundo, 1984. p.28-33.

Canarachea, A.; Hornb, R.; Colibasc, I. Compressibility of soils in a long term field experiment with intensive deep ripping in Romania. Soil \& Tillage Research, v.56, p.185-196, 2000.

Carpenedo, V. Compressibilidade de solos em sistemas de manejo. Porto Alegre: UFRGS, 106p., 1994. Tese Doutorado

Cavalieri, K. M. V.; Arvidsson, J.; Silva A. P.; Keller, T. Determination of precompression stress from uniaxial compression tests. Soil \& Tillage Research, v.98, p.17-26, 2008.

Dexter, A. R., Czyz, E. A.; Gat, O. P. A method for prediction of soil penetration resistance. Soil \& Tillage Research, v.93, p.412-419, 2007.

EMBRAPA - Empresa Brasileira de Pesquisa Agropecuária. Manual de métodos de análises de solo. 2.ed. Rio de Janeiro: CNPS, 1997. 212p.

EMBRAPA - Empresa Brasileira de Pesquisa Agropecuária. Sistema Brasileiro de Classificação de Solos. 2.ed. Rio de Janeiro: Embrapa Solos, 2006. 306p.

Etana, A; Comia, R.A.; Hakansoon, I. Effects of uniaxial stress on the physical properties of four Swedish soil. Soil \& Tillage Research, v.44, p.13-21, 1997.

Figueiredo, C. C.; Santos, G. G.; Pereira, S.; Nascimento, J. L.; Alves Júnior, J. Propriedades físico-hídricas em Latossolo do Cerrado sob diferentes sistemas de manejo. Revista Brasileira de Engenharia Agrícola e Ambiental, v.13, n.2, p.146-151, 2009.

Imhoff, S.; Silva, A. P.; Fallow, D. Susceptibility to compaction, load support capacity, and soil compressibility of hapludox. Soil Science Society America Journal, v.68, p.17-24, 2004.
Keller, T.; Arvidsson J. Compressive properties of some Swedish and Danish structured agricultural soils measured in uniaxial compression tests. European Journal of Soil Science, v.58, p.1373-1381, 2007.

Koch, H. J.; Heuer, H.; Tomanova, O.; Marlander, B. Cumulative effect of annually repeated passes of heavy agricultural machinery on soil structural properties and sugar beet yield under two tillage systems. Soil \& Tillage Research, v.101, p.69-77, 2008.

Krummelbein, J.; Peth, S.; Horn, R. Determination of pre-compression stress of a variously grazed steppe soil under static and cyclic loading. Soil \& Tillage Research, v.99, p.139-148, 2008.

Kutýleka, M.; Jendeleb, L.; Panayiotopoulos, K. P. The influence of uniaxial compression upon pore size distribution in bi-modal soils. Soil \& Tillage Research, v.86, p. 27-37, 2006.

Lima, C. L. R.; Reinert, D. J.; Reichert, J. M.; Suzuki, L. E. A. S. Compressibilidade de um Argissolo sob plantio direto escarificado e compactado. Ciência Rural, v.36, p.1765-1772, 2006.

Lima, C. L. R.; Silva, A. P.; Imhoff, S.; Leão, T. P. Compressibilidade de um solo sob os sistemas de pastejo rotacionado irrigado e não irrigado. Revista Brasileira de Ciência do Solo, v.28, p.945-951, 2004.

Macedo, V. A. M. Compressibilidade de um Podzólico Vermelho Escuro fisicamente degradado e recuperado. Porto Alegre: UFRGS, 1993. 88p. Dissertação Mestrado

Medeiros, J. C. Sistemas de culturas adaptadas à produtividade, recuperação e conservação de solo. Porto Alegre: UFRGS, 1985. 89p. Dissertação Mestrado

Mooney, S. J.; Nipattasuk, W. Quantification of the effects of soil compaction on water flow using dye tracers and image analysis. Soil Use and Management, v.19, p.356-363, 2003.

Richards, L. A. Physical condition of water in soil. In: Black, C.A. (ed.) Methods of soil analysis. Part 1. Madison: American Society of Agronomy, 1965. 770p.

SEPLAG - Secretaria do Planejamento e Gestão do Rio Grande do Sul. http://www.seplag.rs.gov.br. 19 Jan. 2010.

Severiano, E. C.; Oliveira, G. C.; Dias Junior, M. S.; Costa, K. A. P.; Castro, M. B.; Magalhães, E. N. Potencial de descompactação de um Argissolo promovido pelo capim-tifton 85. Revista Brasileira de Engenharia Agrícola e Ambiental, v.14, n.1, p.39-45, 2010.

Silva, A. J. N.; Cabeda, M. S. V. Compactação e compressibilidade do solo sob sistemas de manejo e níveis de umidade. Revista Brasileira de Ciência do Solo, v.30, p.921-930, 2006.

Silva, F. A. S. The Assistat Software: statistical assistance. In: International Conference on Computers in Agriculture, 6., Cancun, 1996. Anais... Cancun: American Society of Agricultural Engineers, 1996. p.294-298.

Silva, H. P. Infiltração de água em um Argissolo Vermelho-Escuro fisicamente degradado em processo de recuperação. Porto Alegre: UFRGS, 1986. 105p. Dissertação Mestrado 
Silva, A. J. N.; Cabeda, M. S. V.; Carvalho, F. G. Propriedades físico-hídricas em Latossolo do Cerrado sob diferentes sistemas de manejo. Revista Brasileira de Engenharia Agrícola e Ambiental, v.13, n.2, p.146-151, 2009.

Silva, V. R.; Reinert, D. J.; Reichert, J. M. Suscetibilidade à compactação de um Latossolo Vermelho-Escuro e de um Podzólico Vermelho-Amarelo. Revista Brasileira de Ciência do Solo, v.24, p.239-249, 2000.

Silva, V. R.; Reinert, D. J.; Reichert, J. M.; Soares, J. M. Fatores controladores da compressibilidade de um Argissolo VermelhoAmarelo Distrófico arênico e de um Latossolo Vermelho Distrófico Típico. I - Estado inicial de compactação. Revista Brasileira de Ciência do Solo, v.26, p.1-8, 2002.
Stone, J. O.; Larson, W. E. Rebound of five one-dimensionally compressed unsatured granular soils. Soil Science Society America Journal, v.44, p.819-822, 1980.

Trautner, A.; Arvidsson, J. Subsoil compaction caused by machinery traffic on a Swedish Eutric Cambisol at different soil water contents. Soil \& Tillage Research, v.73, p.107-118, 2003.

Veiga, M.; Hort, R.; Reinert, D. J.; Reichert, J. M. Soil compressibility and penetrability of an Oxisol from southern Brazil, as affected by long-term tillage systems. Soil \& Tillage Research, v.92, p.104-113, 2007.

Zhang, B.; Horn, R.; Hallett, P. D. Mechanical resilience of degraded soil amended with organic matter. Soil Science Society America Journal, v.69, p.864-871, 2005. 